\title{
Las "cicatrices hermosas": metaautobiografía, género y acción intelectual en Dinosauria soy. Memorias de Graziella Pogolotti ${ }^{1}$
}

\author{
The "beautiful scars": meta-autobiography, \\ gender and intellectual action in Dinosauria soy. \\ Memorias de Graziella Pogolotti
}

\begin{abstract}
JESÚS GÓMEZ-DE-TEJADA
Universidad de Sevilla, Facultad de Filología, España. Correo electrónico: jgomezdetejada@us.es
\end{abstract}

Este artículo sitúa Dinosauria soy. Memorias (2011) de Graziella Pogolotti en el campo transnacional de autobiografías cubanas surgidas tras la Revolución. Primero, se analizan las principales líneas narrativas presentes en la obra, con especial atención al componente meta-autobiográfico y a la perspectiva de género. Tras ello, el estudio parte de la concepción de la autobiografía como acto literario fundamentado en un simulacro referencial que se propone como acción intelectual. Dentro de este marco, plantea la hipótesis según la cual la escritura memorística de la autora pone de relieve una voz femenina que expresa la conciencia del propio desempeño histórico en medio de los condicionamientos provenientes de las relaciones entre el intelectual y la revolución. Finalmente, se concluye que Pogolotti, desde la certeza de la imposibilidad referencial, pretende ofrecer una reconstrucción autobiográfica veraz, vinculada al examen de conciencia, con el deseo principal de expresar y cumplir su vocación de compromiso como intelectual revolucionaria.

Palabras claves: Graziella Pogolotti, intelectuales y Revolución cubana, autobiografía, memorias, literatura cubana e hispanoamericana.

This article places Graziella Pogolotti's Dinosauria soy. Memorias (2011) in the transnational context of Cuban autobiographies written after the Revolution. First, it analyzes the major narrative threads present in the work, paying special attention to the meta-autobiographical component and the gender perspective. Following this, the study takes the conceptualization of the autobiography as a literary act based on a referential simulacrum introduced as an intellectual action. Within that framework, the

\footnotetext{
${ }^{1}$ Este artículo ha sido posible gracias a un proyecto financiado por el Programa CONICYT, FONDECYT Postdoctorado 2015, No 3150177, titulado: "La isla y sus espejos: redes de la memoria cubana del siglo XXI", del que he sido investigador responsable entre 2015 y 2017. Agradezco a la Dra. Graziella Pogolotti las entrevistas que me concedió en La Habana en 2016 y 2017.
} 
article introduces the hypothesis according to which the author's memoir style reveals a female voice who expresses the awareness of her own historical role amidst the constraints arisen from the relationship between the intellectual and the Revolution. Finally, this analysis concludes that Pogolotti, from the knowledge of the impossible referentiality, offers a genuine autobiographical reconstruction, close to self-examination, with the main desire of fulfilling her commitment as a revolutionary intellectual.

Key words: Graziella Pogolotti, Intellectuals and Cuban Revolution, Autobiography, Memoirs, Cuban and Spanish American Literature.

[C]ontrariamente a lo que pensaba Flaubert, el balance de la vida no se reduce a un triste mechón de cabellos entrecanos. Hay cicatrices hermosas, las que nacieron del empeño por mantener el mundo y sobre todo, las que se hicieron en el esfuerzo por transformarlo (Pogolotti 1987: 8).

\section{INTRODUCCIÓN}

Graziella Pogolotti Jacobson (París, 1932) vivió su primera infancia envuelta en los grandes conflictos de la Europa de finales de los años treinta, previos a la Segunda Guerra Mundial, que determinaron su llegada a Cuba -en noviembre de 1939. Así, surgió en ella una conciencia histórica que alcanzó la plenitud durante la Revolución cubana. La familia, la amistad, la enfermedad, la metarreflexión y lo intelectual son las principales líneas de Dinosauria soy. Memorias (2011). Entre ellas, destacan especialmente dos: por un lado, aquella donde reflexiona sobre lo memorístico y lo autobiográfico; por otro lado, aquella que relata la identificación y participación del yo enunciado respecto a los objetivos de cambio radical que se ponen en marcha desde el Gobierno de Fidel Castro. Por ello, el artículo se detiene primero en el análisis de la idea de la imposible reconstrucción íntegra del pasado por medio de la memoria y en el examen de la perspectiva de género, que emanan de este texto autorreflexivo. En segundo lugar, se demora en el estudio de la obra como la acción intelectual de una voz femenina que expresa la conciencia del propio desempeño histórico en medio de los condicionamientos provenientes de las relaciones entre el intelectual y la revolución. Desde este foco, Pogolotti testimonia sobre la vivencia de los hechos principales en los que actuó, según reitera, con sobrio protagonismo y construye una imagen del desarrollo cultural del país durante medio siglo de sucesivas transformaciones.

\section{LA AUTOBIOGRAFÍA CUBANA TRAS EL TRIUNFO DE LA REVOLUCIÓN}

A diferencia de otros géneros, la autobiografía no es una escritura especialmente desarrollada en Cuba a partir de 1959. En los años sesenta, con la mirada puesta hacia el futuro en plena efervescencia revolucionaria aún no es hora de hacer recuento, aunque ya 
aparecen las primeras manifestaciones testimoniales que dejan constancia de la vida en Cuba antes de $1959 .{ }^{2}$ En la década de los setenta, se consolida hegemónicamente la modalidad del testimonio, que se ve propulsada por el concurso Casa de las Américas que instaura una sección dedicada a esta modalidad en $1970 .{ }^{3}$ En ese momento, la autobiografía dispone de poca consideración y espacio frente a un nuevo género que, según Casaus (1986), se convirtió en un instrumento adecuado para la recuperación y el mantenimiento de la memoria colectiva, el desarrollo del lenguaje, las costumbres y el ser popular, y la proyección de la cultura de las masas -cuya alfabetización fue objetivo principal desde el inicio de la Revolución-, y que en definitiva, continúa Casaus en su apología del testimonio, hizo "considerables aportes [...] al proceso de creación de nuestra cultura socialista" a través de "su capacidad de operar sobre los hechos inmediatos" y proporcionar "una eficaz comunicación con sus interlocutores" (330-331). ${ }^{4}$

A partir de los ochenta, comienzan a aparecer las primeras narraciones autorreferenciales desde fuera de Cuba: Carlos Franqui, Retrato de familia con Fidel (1981); Heberto Padilla, La mala memoria (1989); y Reinaldo Arenas, Antes que anochezca (1992) (ver Clark 1999). No obstante, es a partir de los ańos noventa cuando la escritura autobiográfica desde fuera de la Isla irrumpe en el mercado editorial con más fuerza y se prolonga hasta la actualidad: Eliseo Alberto, Informe contra mí mismo (1997); Josefina de Diego, El reino del abuelo (1993); Nivaria Tejera, Espero la noche para soñarte, Revolución (2002); Manuel Díaz Martínez, Solo un rasguño en la solapa (2002); Lorenzo García Vega, El oficio de perder (2004), entre otros muchos títulos más. A este conjunto se añade el colectivo cubano-americano, que cuenta tanto con una fuerte producción autobiográfica (Gustavo Pérez Firmat, Carlos Eire, Pablo Medina, Mirta Ojito) como con un conjunto de textos críticos volcados en su análisis (ver Álvarez-Borland 1998: 49-87).

Junto a esta producción autobiográfica exterior a la geografía insular, hay también una perteneciente a la intelectualidad del interior: los textos de Loló de la Torriente ( $M i$ casa en la tierra [1956], llamada en segunda edición ampliada y corregida Testimonio desde dentro, 1985), Renée Méndez Capote (Memorias de una cubanita que nació con el siglo, 1963) y Marcelo Pogolotti (Del barro y las voces, 1968). Posteriormente, además de Diarios [193949/1956-58] (1994), de Lezama Lima y los fragmentos autobiográficos de Virgilio Piñera ("La vida tal cual", 1990) pueden citarse entre otras las autobiografías de Dora Alonso (Agua pasada, 1981), Nicolás Guillén (Páginas vueltas, 1982), Raúl Martínez (Yo, Publio,

\footnotetext{
${ }^{2}$ Entre los más conocidos están los títulos de Miguel Barnet, Biografia de un cimarrón (1966) y Canción de Rachel (1969).

${ }^{3}$ Miranda (2008) señala varias líneas temáticas que confluyen cronológicamente en el desarrollo del testimonio: "la lucha insurreccional", "la lucha guerrillera en las montañas", "la lucha clandestina", "la defensa de la revolución", "la construcción de la nueva sociedad" y "los que abandonaron el país y el internacionalismo proletario" (Miranda 507-520).

${ }^{4}$ Similar opinión sostiene Pérez-Hernández (2016: 39-42) que cita "Defensa del testimonio" (1981), de Casaus y "Autobiografía, testimonio, ficción: una relación delicada" (1997), de Freita Reis como fundamentación.
} 
confesiones de Raúl Martínez, 2007), Pablo Armando Fernández (La mano del tiempo, 2012) o Graziella Pogolotti (Dinosauria soy. Memorias 2011). ${ }^{5}$

Esta pluralidad permite proponer una aproximación globalizadora, integrada en el marco conceptual del transnacionalismo que puede ser usada para explicar las redes de interconexión entre los núcleos cubanos de dentro y fuera de la Isla. Se consideran estas autobiografías como parte de la trama cultural y del pensamiento que dialoga en torno a un espacio identitario que pretende rebasar las fronteras geográficas. Desde este punto de vista, el análisis literario e ideológico de estas autobiografías como conjunto ofrece una perspectiva complementaria y enriquecedora, que se integra en la reconstrucción del imaginario personal y colectivo cubano del último medio siglo. ${ }^{6}$

\section{Los LINEAMIENTOS DISCURSIVOS EN DINOSAURIA SOY}

La escritura del yo ha recorrido un camino prolongado durante el que, desde un punto de vista epistemológico o pragmático, se han debatido los aspectos que determinan su realización y lectura hasta situarse en un relativo equilibrio encontrado fuera de la ilusión referencial y el reduccionismo textual.7 La recepción del texto autobiográfico como propuesta de existencia verídica y la concepción de este como auto-narración del yo a través de un acto ético o dialógico -apelación al tứ ${ }^{8}-$ se articulan con la inevitable figuración del autor erigido en narrador y protagonista.

\footnotetext{
${ }^{5}$ La relación de títulos y autores no puede ser exhaustiva dados los límites de extensión del artículo. Más información sobre la producción autobiográfica cubana puede encontrarse en Rojas (2006: 378-413) y en el artículo citado de Pérez-Hernández (2016).

${ }^{6}$ Esta perspectiva global se basa en la visión posible de la Cuba contemporánea como un espacio transnacional caracterizado por el regular intercambio ideológico, cultural y económico entre la Isla y los distintos grupos afincados en el exterior (Fernández 2005: XV). Este transnacionalismo se configura a través de los diferentes desplazamientos, geografías y generaciones y por el mantenimiento de la identidad original por parte del sujeto migrante (Weimer 2008).

${ }^{7}$ Las formas autobiográficas -autobiografías, memorias, diarios, epistolarios- se construyen sobre una característica tensión entre la dimensión real y la dimensión ficcional del yo textualizado. Representantes de esta polaridad son Wilhelm Dilthey y Paul de Man. Mientras que Dilthey establece una plena correspondencia entre vida narrada e historia vivida, De Man niega a estos textos un estatuto genérico propio al rechazar la relación analógica entre el yo empírico y el yo construido retrospectivamente a través del lenguaje. El pacto autobiográfico, propuesto por Philippe Lejeune como cauce para fijar en el texto la marca de un referente externo, supone la identificación del autor y del biografiado a partir de la firma que acompaña el título de la obra.

${ }^{8}$ En este sentido, resulta sugestiva la teoría de Loureiro (2006), que parte de las ideas de Levinas, para presentar la autobiografía como un acto ético: "La autobiografía no es una restauración del pasado sino un acto singular de autocreación como respuesta, responsabilidad y promesa (de verdad). Como tal, este acto es siempre dialógico, está dirigido al otro, y por lo tanto es siempre intrínsecamente contestable e incompleto. [...] si la autobiografía fracasa necesariamente como empresa cognoscitiva, triunfa siempre como acto performativo, ético, dirigido al otro: aunque la autobiografía nunca puede representar la verdad, siempre presentará el deseo del sujeto de autoconocerse y su promesa de verdad" (Loureiro 37-38).
} 
Bruss (1991) introduce la comprensión de la autobiografía como un acto ilocutivo y, en última instancia, como un acto literario, cuyas características no pueden determinarse apriorísticamente, sino que son establecidas en cada ocasión por el contexto socio-histórico. Como señalan Smith y Watson (2001) es el marco contextual, en cada época concreta, el que pone a disposición del autobiógrafo una serie de modelos de enunciación, de patrones ideológicos, de tipos nocionales de la identidad que vehiculan el modo en que los diferentes elementos del acto autobiográfico se concretan singularmente en el texto para dejar huella de la multiplicidad y fragmentariedad de sus yoes -yo histórico, yo narrador, yo narrado, yo ideológico. ${ }^{9}$

Desde estos condicionantes, se estudia Dinosauria soy a través de los aspectos retóricos que construyen su singularidad formal, los lineamientos discursivos que sustentan la enunciación, la consideración del marco contextual como determinante de modelos discursivos e ideológicos específicos y la acción intelectual que la obra supone bajo circunstancias político-sociales concretas. Especialmente, por su significación en la obra, se presta atención a los componentes meta-autobiográficos, a la perspectiva de género y al empleo del texto autorreferencial como tribuna para intervenir en un ámbito distinto al campo literario.

Entre los recursos prosísticos sobre los que se edifica la cualidad estética del texto caben citarse el empleo de la intertextualidad (como estructura de la narración, como cita o como alusión), ${ }^{10}$ el carácter circular del relato en numerosos capítulos a partir de una evocación inicial o de la presentación de un escenario físico desde el que se produce la retrospección, la construcción retórica de un tiempo no lineal y la insistencia metaautobiográfica. El tejido narrativo configurador de la subjetividad y de la temporalidad del sujeto autobiográfico -sujeto enunciador y sujeto enunciado- se desarrolla a través de una prosa elaborada, de riqueza académica, culturalista y salpicada de metáforas. La narración anecdótica y retrospectiva de los recuerdos sintetizados y orgánicamente resemantizados se entreteje constantemente -deslizándose de una a otra- con la prosa ensayística que bebe de la reflexión vitalista, ética y ontológica y del amplio bagaje cultural de la autora, henchido de citas literarias, referencias artísticas y alusiones cinematográficas. Desde el presente consolidado en la experiencia, la autobiógrafa irradia su pensamiento hacia el pasado abierto a la expectativa del futuro (Pogolotti 2011: 60). Este porvenir se proyecta hacia las nuevas generaciones, con respecto a las cuales la palabra de Pogolotti, legitimada por la convergencia de pensamiento con Fidel Castro, según ella misma establece, abre una amplia fractura generacional. La conciencia de esa grieta de visión y de actitud frente al mundo

\footnotetext{
${ }^{9}$ Los componentes propuestos por Smith y Watson son la memoria (memory), la identidad (identity), la experiencia (experiency), la corpereidad (enbodyment) y la agencia (agency) (Smith y Watson 50 y ss.).

${ }^{10}$ En busca del tiempo perdido (1913), de Marcel Proust y La Cartuja de Parma (1839), de Stendhal son los intertextos más notorios y los que llegan a alcanzar un carácter simbólico, temático y estructural en Dinosauria soy. El conocimiento de estas dos obras y la predilección hacia ellas, condujo a Pogolotti a escribir sendos prólogos para las ediciones cubanas de las mismas.
} 
lleva a la autora a proclamar enfáticamente al final de su relato, con una mezcla de orgullo y cierto abatimiento, "[p] or eso, dinosauria soy" (Pogolotti 285).

Los ejes del discurso autobiográfico que vertebran la narración de la obra son el espacio personal de la familia y la amistad, la enfermedad, la reflexión alrededor del hecho memorístico, y la acción intelectual en torno al compromiso histórico y revolucionario asumido por la autora. El espacio concedido a lo personal es reducido por Pogolotti a consideraciones y retrospecciones relativas a la familia y la amistad. La identidad de Pogolotti viene marcada en la autobiografía como mujer blanca, italo-ruso-cubana, intelectual pequeñoburguesa, perteneciente a la generación de los ańos 50 y 60 , procedente de una familia de emigrantes, atea y de ideas socialistas fuertemente implicada en el proceso revolucionario cubano. ${ }^{11}$ La línea del relato de los ancestros discurre por la constatación de un linaje de emigrantes de orígenes italiano (los Pogolotti) y ruso (los Jacobson) dispersos por varios países y continentes. La narración de la propia emigración desde Italia a Cuba, por un lado, incide en la conmoción provocada por la pérdida y por la nostalgia del mundo prístino de la primera infancia. Por otro, este eje narrativo hace fuerte hincapié en los sentimientos generados por el proceso de adaptación al nuevo entorno y por el arraigo progresivo culminado en una irrenunciable identificación con el país de acogida. ${ }^{12}$ Las relaciones con los padres y las personalidades de estos son focalizadas a modo de homenaje en sendos capítulos dedicados a cada uno de ellos en un tono de examen de conciencia atravesado por la sinceridad y el esfuerzo comprensivo. El círculo de amistades descrito se abre desde la infancia italiana y cubana hasta la formación universitaria, los grupos literarios y el desempeño académico e institucional. La evocación de nombres está signada por el distanciamiento impuesto por los años y la soledad desde la que se escribe.

La enfermedad vertebra desde el comienzo una de las trayectorias constructoras de la subjetividad del yo. La ceguera de los Pogolotti se convierte en canal de corporeidad para la memoria. La invidencia como fatum familiar se introduce a través de la temprana pérdida del padre (el pintor Marcelo Pogolotti) del sentido de la vista, de modo que ya llega ciego a Cuba. La ceguera estimula la mirada hacia el pasado de un modo preciso, igual que la inminencia de la oscuridad condicionó la urgencia en ella por asimilar y aprehender la realidad antes de que todo desapareciera. También determina la relación entre padre e hija, y la mirada retrospectiva de ella sobre él y, en última instancia, sobre sí misma. Ser lazarillo del padre lleva a Pogolotti a establecer particulares interacciones con la ciudad y con la atmósfera intelectual que rodeaba al pintor. Desde el testimonio del padecimiento ajeno, el sujeto autobiográfico pasa a narrar las progresivas tinieblas que, indefectibles, se abaten

\footnotetext{
${ }^{11}$ Según Smith y Watson, "las identidades están marcadas por muchas categorías: género, raza, etnia, sexualidad, nacionalidad, clase, generación, genealogía familiar, ideología religiosa y política, por citar las más obvias" (2001: 33; mi traducción).

${ }^{12}$ Pérez-Hernández (2016) analiza este aspecto como un rasgo fundamental en la construcción autobiográfica de la escritora: "Leídas fuera del marco documental que testimonia una época o determina la filiación política de su autora, Dinosauria soy parece buscar, de forma contradictoria, la lectura de una emigrante europea en el Caribe" (58).
} 
sobre sus propios ojos. El relato de la dolencia se hace directo y es el propio sufrimiento ante la acción de las cataratas irreversibles el que ocupa la enunciación: dolor ante el descubrimiento, conciencia de la herencia genética, peregrinaje hospitalario, expectativas de curación, frustración ante los sucesivos fracasos quirúrgicos, pérdida gradual de la visión, oscuridad definitiva. Las cicatrices oculares -operaciones, desprendimientos de retina, cataratas- producen una corporeidad de la memoria que se desarrolla como un "largo itinerario hasta las sombras" (Pogolotti 260). La ceguera definitiva potencia la tendencia de la escritora hacia lo sacrificial y lo ascético, propia de su espíritu y acorde con el ejemplo guevariano (Pogolotti 259).

\section{La METARREFLEXIÓN AUTOBIOGRÁFICA Y LA PERSPECTIVA DE GÉNERO}

La concepción de la autobiografía que emana de Dinosauria soy no se corresponde con aquella que equipara el yo vivido con el textualizado, sino que es plenamente consciente de la disyunciones de la identidad y del tiempo que se establecen en, lo que se ha llamado, el simulacro autobiográfico. ${ }^{13}$ Según Pogolotti, el pasado está "irremediablemente perdido" (Pogolotti 5) y es esta certeza la que hace que su imagen de nińa en una aldea italiana "se [1]e proyect[e] como un daguerrotipo" (Pogolotti 7). Del mismo modo, la lectura de uno de sus diarios escritos décadas antes le provoca la falta de reconocimiento de los pensamientos expresados por un yo que ya no es el actual: "Rescaté hace poco un diario perdido. Nada recuerdo de lo que entonces anotaba. [...] la persona que procuraba desahogo para sus angustias en la página en blanco ha dejado de existir. Me resulta tan ajena como un desconocido paseante callejero. Mi verdad posible está en lo que sobrevive del ayer y morirá mañana" (Pogolotti 289-290). Por ello, afirma que "el pasado no se recupera. Se restaura" (Pogolotti 7). Las memorias que la autora transcribe en Dinosuria soy son la reconstrucción de lo que llama un cuarto tiempo que describe como resultado del entremezclamiento y la contaminación de los otros tres: pasado, presente y futuro. Giaveno, el pueblo de la infancia al que regresa una madura Pogolotti en busca de un espacio potenciador de la capacidad evocadora, se opone a Combray, escenario literario que Proust había convertido en el perfecto estímulo para recordar:

Combray no existe. El cuarto tiempo de la memoria está hecho de impurezas, de contaminaciones, de historia, de olvidos y compromisos, de pasiones, de falsas cronologías y de relojes mal acoplados, indetenible y escurridizo. Esa es su verdad. Es un tiempo que no se recupera. Se salva porque se reconstruye y se reinventa día a día, porque se vuelve a escribir sobre la experiencia virgen de cada mańana (Pogolotti 10).

\footnotetext{
${ }^{13}$ Scarano (1997) señala el simulacro referencial como uno de los niveles constituyentes de la autobiografía, ya que la "poética de la simulación diseńa desde su comienzo la lectura-escritura de un texto autobiográfico" y es en este nivel precisamente donde reside "la fuerza elocutiva del discurso" (Scarano 160).
} 
Lo meta-autobiográfico, es decir, la alusión al acto de escribir la propia autobiografía, supone la intromisión del presente de esta acción en el pasado reconstruido textualmente. Para Scarano, "[l]a autobiografía es el tránsito desde un pasado (byos) al orden de los signos (graphê) para configurar un sujeto (autos) desde sí mismo" y en este acto, afirma Scarano (1997), "la temporalidad se bifurca en un presente del relato que opera la construcción y un pasado de la vida que funciona como objeto focalizado" (157). La mención al acto de creación autorreferencial, que Scarano considera una constante en la retórica del género, cobra gran vigencia también en Dinosauria soy:

Mientras escribo surge en mi memoria, insistente como un martilleo, la célebre frase de Klausewicz: 'La guerra es la continuación de la política por otros medios'. Pienso ahora, cuando intento recuperar fragmentos de mi pasado, operación riesgosa, siempre contaminada por un presente diluido en el transcurrir de un día tras otro, que mi vida recorrió un camino inverso (Pogolotti 40).

Parte de esta especularidad es la recreación textual de un lugar físico convertido en escenario desde el que el yo narrador configura el yo narrado (Scarano 160-161). A través de este recurso, el presente de la narración autobiográfica diluye los límites entre escritura y evocación. Estas explicitaciones espaciales se concretan en la representación de diferentes localizaciones y escenas: desde el sitio de escritura de la obra que el lector tiene ante sí hasta otros lugares de recuperación oral colectiva de carácter familiar o cultural. En cuanto al primero, Pogolotti recrea el escenario de gestación de Dinosauria soy: la escritura dominical y solitaria, junto a la ventana abierta de su piso habanero, sentada ante una vieja máquina Underwood cuyo teclear se convierte en un diálogo con la página en blanco. Respecto de los segundos, destaca la casa familiar en Giaveno, pueblo italiano cercano a Turín, donde Pogolotti pasó su primera infancia y donde ya adulta se reúne con dos mujeres de su familia con el propósito, en gran medida frustrado, de lograr una reconstrucción cooperativa del pasado.

Específicamente, Giaveno, como sitio de la memoria, permite a la autora la diferenciación de tres modos de memoria femenina. En este pasaje recurrente, relata la construcción de un pretérito habitualmente esquivo en un escenario de reunificación femenino, donde tres mujeres de su familia, incluyéndola a ella misma, asumen el legado de una estirpe migrante. Sobre la trascendencia de la autobiografía escrita por mujeres, Loureiro (1994) afirma que "[l]o autobiográfico constituye un elemento esencial del feminismo en lo que tiene de proyecto de autoconocimiento y liberación" (29) y refuerza esta idea recuperando las palabras de Gayle Greene (1994) en las que asevera que "el feminismo aconteció cuando las mujeres aprendieron a decir 'yo'” (12).

Pogolotti atribuye distintos roles y actitudes memorísticas a cada una de las tres mujeres. A través de una de ellas, recrea, no sin reconocimiento y afecto, una visión esencialista y mitológica de la mujer como sustentadora de la intrahistoria familiar (36-37) desde una posición ancilar a los hechos del hombre, es decir, su acción conservadora se dirige a preservar la memoria masculina. Esta figura concuerda con la afirmación de Smith en los comienzos de 
la crítica autobiográfica femenina, que apuntaba que aunque el hecho de que la mujer tomara la palabra para recrear la propia historia suponía ya una transgresión del discurso falocéntrico impuesto culturalmente por el hombre, ello no impedía que la pulsión autobiográfica femenina pudiera seguir relegada al ámbito doméstico o a perpetuar la genealogía del hombre al narrar la biografía de los maridos, hermanos, hijos (Smith 1991: 110). Se trata de lo que Peterson llama un modelo del "domestic memoir (memoria doméstica), relato de una experiencia relacional' (cit. en Araújo 1997: 38). La descripción de la otra familiar que participa en el encuentro en Giaveno es más distanciada y puede asociarse a un tono de reconvención ante una figura silenciosa, superficial, aburguesada, de memoria aparentemente estéril. Frente a ellas, Pogolotti inscribe su "autorrepresentación pública" como mujer y, según las palabras de Smith (1991), se interna en la "narración herética" -frente al yo canónico masculino - para hacer "surgir significado y autoridad autobiográfica" (Smith 120-121).

Sin embargo, en Dinosauria soy no hay una exaltación, una reivindicación o una denuncia directas de las condiciones de la mujer en la sociedad revolucionaria. Según la autora declara en una entrevista, se trata de un "feminismo implícito" (Gómez-de-Tejada 2017: 196). El enfoque genérico-sexual de Pogolotti en esta reconstrucción autorreferencial se enhebra en la adscripción sin fisuras a la acción intelectual y pública. La narración de las actividades desempeñadas en los distintos puestos ocupados bajo los auspicios del Gobierno revolucionario -en la universidad, en la UNEAC, en Casa de las Américas, en el Ministerio de Cultura, en la Biblioteca Nacional José Martí, en el proyecto Teatro del Escambray, en la Facultad de Teatro del Instituto Superior de Arte, en La Gaceta de Cuba, en sus responsabilidades periodísticas- muestran una intelectual voluntaria y conscientemente integrada en el proceso histórico cubano. Su palabra y su mente se presentan caracterizadas por la autorreflexión, la mesura, la exactitud y la pertinencia, ocupando por derecho propio el espacio común de participación revolucionaria.

Aun así, en ocasiones, se reconoce la explicitación de la diferencia femenina apenas aludida en el contraste rápido y concreto, en el pasaje de liberación mencionado de modo mínimo, en el foco naturalmente expuesto sobre la biografía de las protagonistas, en el recuento de parejas en las que el hombre y la mujer se sitúan en el mismo ámbito. Es al volver la mirada al otro, cuando se observa, sutil pero constante, la enumeración profusa, junto a los nombres masculinos, de las figuras femeninas que fueron jalonando el decurso histórico y vital de la autobiógrafa.

\section{LA VIGILIA PERMANENTE: LA AUTOBIOGRAFÍA COMO ACCIÓN INTELECTUAL}

La escritura autobiográfica se puede justificar por el deseo de dirigirse al otro y constituirse como yo en esa acción. Desde una postura intelectual, este acto adquiere trazos definidos. Como es sabido, Pierre Bourdieu (2005) entiende por intelectual el escritor que "desde las normas propias del campo literario [...] interviene en el campo político" (197). Gilman (2003) apunta que el campo intelectual, para este autor, 
se constituye como un espacio de lucha y competencia, en el que cada uno de los miembros ve restringida la acción individual, en la medida en que está inserto en una organización que posee una legalidad particular y propia. La noción de campo permite establecer una sociología de los intelectuales que puede dar cuenta de las diversas alternativas de cada uno de los miembros, en función de las coyunturas históricas, políticas, económicas y sociales en las que el campo funciona en cada momento dado. De ese modo, es posible formular hipótesis de conjunto y establecer el campo de alternativas de cada uno de sus miembros (16).

A la luz de esta perspectiva, la autobiografía puede analizarse como un acto intelectual en el que el yo estructura su autorrepresentación como un acto ético -ilocutivoy supone una utilización de la tribuna literaria como cauce para intervenir en el campo político con el armamento de veracidad con que el protocolo de lectura del género provee al lector. Según Bruss (1991), la concepción de la autobiografía como acto literario implica una definición de la misma alejada de esencialismos que considere el contexto en el que la acción ilocutiva se produce. De modo esquemático, cabe afirmar que la escritura de Dinosauria soy, desarrollada a lo largo de fines de los años noventa del siglo XX y la primera década del siglo XXI, hasta su publicación como libro en 2011, se enmarca en el Periodo Especial en Tiempos de Paz que dio lugar a un contexto de revisionismo del carácter socialista soviético de las directrices gubernamentales cubanas, de relativa flexibilización de los controles culturales, y de la expansión de las relaciones entre la comunidad de dentro y fuera de la Isla hasta permitir hablar de una Cuba transnacional.

La disparidad de experiencias e ideologías, amparadas por ese transnacionalismo integrador, posibilita el reconocimiento de diferentes modelos discursivos en el seno del conjunto de la narración autobiográfica cubana. Desde la idea de acción intelectual, los escritos autorreferenciales cubanos se enmarcan en el juego de las políticas de intervención del pasado que Rojas (2002) ha llamado nudos de la memoria y que aluden a las políticas de atar y desatar o a las de condena, perdón y olvido arbitradas desde los polos integrados por las comunidades identificadas con la Revolución, la oposición y el exilio (383). Igualmente, si se consideran las modalidades que Hirschman (1977) establece como acciones en favor y en contra de las empresas y los gobiernos, los actos intelectuales pueden considerarse desde tres categorías: voz, salida y lealtad. Según Colomer (1998), frente a las respuestas denominadas voz y salida, que la ciudadanía puede adoptar como forma de demostrar su rechazo a la situación gubernamental que lo afecta, la lealtad supone la explicitación de la conformidad con el estado político del país (6).

En este contexto, la reconstrucción memorística en Dinosauria soy ofrece la autofiguración de un sujeto plenamente consciente de la responsabilidad histórica ante el proceso de transformación política, económica, cultural y social iniciado en $1959 .{ }^{14}$ Esta

${ }^{14}$ Ya en el discurso de llegada a La Habana del 8 de enero de 1959, Fidel Castro llamaba la atención sobre
este aspecto: "Creo que es este un momento decisivo de nuestra historia: la tiranía ha sido derrocada. La alegría es 
autobiografía se convierte en un análisis del cumplimiento de la labor revolucionaria y de la integración en la acción colectiva. Junto a ello, se da la circunstancia de que el impulso que determina la escritura de la obra no tiene un carácter espontáneo, sino que es externo, puesto que la autora es solicitada para contar su historia por escrito. Según señala Pogolotti, Luisa Campuzano, directora de la revista Revolución y Cultura, le propone la redacción de la autobiografía. De tal modo, que los primeros capítulos aparecen en las páginas de la revista a lo largo de los números del ańo $2001^{15}$. La escritura, por tanto, se hace desde los auspicios y la promoción de instituciones culturales revolucionarias. ${ }^{16}$ De este modo, el acto literario que supone la creación y publicación de la obra puede ser analizado como una acción intelectual de lealtad a la Revolución. Esta labor de servicio no empańa la evidencia de una perspectiva crítica canalizada por el examen de conciencia personal y permitida por el revisionismo propio del Periodo Especial. ${ }^{17}$

Desde el comienzo, Pogolotti representa su existencia como una sucesión de acontecimientos concatenados con el devenir del tiempo que le correspondió vivir. La infancia determinada por la convulsa Europa, la juventud universitaria marcada por el rechazo a la corrupción republicana y a la dictadura de Batista, y, finalmente, la madurez caracterizada por la integración en la Revolución. La responsabilidad histórica, que Fidel Castro y Ernesto "Che" Guevara destacaron como uno de los axiomas del revolucionario cubano, vertebra la narración autobiográfica de Pogolotti desde su salida de Italia y Francia en los años treinta por la ascendencia del nazismo. Ese deber autoconsciente, la afinidad con

inmensa. Y sin embargo, queda mucho por hacer todavía. No nos engańamos creyendo que en lo adelante todo será fácil; quizás en lo adelante todo sea más difícil” (Castro [1959]; mi énfasis).

${ }^{15}$ Los cinco capítulos publicados en Revolución y Cultura a lo largo de cinco números son "La bulla" (2001a), "El paso de las flotas" (2001b), "La familia se retrata" (2001c), "Desde la colina" (2001d), "Reina del mar" (2001e). En ellos focaliza su llegada a Cuba, la etapa final de su infancia y juventud y los años de formación universitaria en La Habana y en Europa. En 2006, se publicó uno más en la misma revista: el titulado "Zizou" dedicado a la figura de Eva Fréjaville, durante un tiempo esposa del pintor Carlos Enríquez.

${ }^{16}$ El origen de la persuasión (coaxer) que lleva a un autor a escribir una autobiografía, según Smith y Watson (2001), "se considera uno de los componentes del acto autobiográfico" y puede ser "cualquier persona o institución o un conjunto de imperativos culturales que piden o provocan que las personas cuenten sus historias" (Smith y Watson 50; mi traducción). Pogolotti explicita esta circunstancia en los paratextos y peritextos correspondientes a la obra. Por un lado, en el propio libro, en los "Agradecimientos" finales donde reconoce su gratitud hacia "Luisa Campuzano por imponerle la tarea" y a "Margarita Mateo [Palmer], por el impulso final". En cuanto a los peritextos, en una entrevista reconoce que "En realidad, no escogí el momento. A mí me incitaron a escribir las memorias, y lo fui haciendo poco a poco, en los ratos de que disponía. Por eso los relatos se eslabonan a través de varios años de escritura. En vista de que no fue un proyecto que surgió de manera espontánea, y que lleva un buen tiempo caminando, cuando creí haber concluido, entregué el mecanuscrito a la UNEAC” (Cremata 2017: 208-209).

${ }^{17}$ Aunque la continuidad de la presión del Estado se hace evidente en hechos como la censura a la película Alicia en el pueblo de las Maravillas (1991), de Daniel Díaz Torres, y las consecuencias represoras sobre los firmantes de la Carta de los Diez (1991), "a partir de la crisis de los ańos noventa [la relación de los intelectuales con la Revolución tiende a] trascender de una conflictividad centrada en la política cultural para asumir una presencia en la res publica como agencia crítica del proceso" (Bacallao-Pino 2015: 63). 
el proceso revolucionario y su incontrovertible tradición, formación y vocación intelectual la llevan a vincular su actividad institucional y académica a los modelos culturales propulsados por la política del nuevo Gobierno en un momento -nos cuenta- donde "[d] esapareció la frontera entre el día y la noche" y la "vigilia era permanente" (Pogolotti 108). ${ }^{18}$

Las reflexiones en torno a la acción intelectual son abundantes. Las palabras de Pogolotti hacen referencia continua al llamado de la Historia, convertido en premisa revolucionaria: "[l]a Revolución me ofreció la posibilidad de participar en la construcción de un país. Y no me arrepiento de haber optado por los riesgos y el sacrificio. Cada pequeńa victoria me deparó instantes de incomparable felicidad" (Pogolotti 288). ${ }^{19}$ A lo largo de las páginas, da cuenta de las sucesivas obligaciones que afrontó en relación a la cultura y la educación a partir de los años sesenta con la intención de dejar constancia de los hitos político-culturales emprendidos en la Isla: el papel desempeńado en el surgimiento de la nueva Escuela de Letras y en el del Grupo de Teatro del Escambray; la dirección de la Facultad de Artes Escénicas del Instituto Superior de Arte, la labor como vicepresidenta de la Unión de Escritores y Artistas de Cuba. En todos esos hechos confiesa una "voluntad de participar en un proyecto de transformación humana y social", dentro del cual asevera: "No he protagonizado hazañas, aunque he percibido el reflejo de lo grande en el hacer cotidiano de muchos" (Pogolotti 2011: 290). ${ }^{20}$

La descripción que Pogolotti hace de su participación en esta tarea intelectual es de tono explícitamente moderado. Este procedimiento retórico se apoya en tres aspectos fundamentales: la afirmación de su condición de actor distanciado jerárquicamente de las principales figuras rectoras del país, la aseveración de no haber participado directamente en los hitos más notorios en la relación entre Gobierno e intelectuales ("como quien observa un espectáculo desde las gradas", 141), y la definición de la propia actividad como parte de una

${ }^{18}$ Este momento de efervescencia revolucionaria tuvo un carácter internacional y concentró la mirada de muchos otros países hispanoamericanos y europeos sobre la Isla. Prolongada durante los sesenta y los setenta, según argumenta Gilman, la época "se caracterizó por la percepción compartida de la transformación inevitable y deseada del universo de las instituciones, la subjetividad, el arte y la cultura, percepción bajo la que se interpretaron acontecimientos verdaderamente inaugurales, como la Revolución Cubana, no sólo para América Latina sino para el mundo entero" (33).

${ }^{19}$ En el ámbito académico, Pogolotti deja constancia de su preocupación por las relaciones entre el intelectual y el Estado en Polémicas culturales de los 60 (2006), volumen compuesto por una serie de artículos focalizados en este aspecto del panorama cubano y que la autora selecciona y prologa.

${ }^{20}$ Esta línea de acción concuerda con las directrices guevarianas, expuestas en "El socialismo y el hombre en Cuba" (1965), que determinan que labor principal de la revolución es "educar al pueblo" y que el intelectual debe ser parte de este empeño colectivo (Guevara 1975: 108). También se ajusta a las palabras de Fidel Castro durante el discurso de clausura del I Congreso Nacional de Educación y Cultura (1971): "nosotros en el campo de la cultura tenemos que promover ampliamente la participación de las masas y que la creación cultural sea obra de las masas y disfrute de las masas. Y que los mejores valores que ha creado la humanidad en todos los siglos, desde la literatura antigua, las esculturas, las pinturas, igual que lo fueron los principios de la ciencia, la matemática, la geometría, la astronomía, puedan ser patrimonio de las masas, puedan estar al alcance de las masas, puedan comprenderlas y disfrutarlas las masas" (Castro 1971). 
labor colectiva y cotidiana ("desde el anonimato, a la manera de los antiguos constructores de catedrales, [cada día, contribuía] a modelar un país y una cultura”, 142).

Frente a las autobiografías de personajes protagónicos de la historia intelectual de la Revolución cubana, Pogolotti se propone como un actor marginal, apartado de los grandes eventos, tan solo partícipe en los sucesos cotidianos. En este sentido, coincide con la concepción tradicional de la autobiografía femenina que señala que la mujer, desde el espacio subalterno al que ha sido relegada, tiende a auto-justificar su escritura desde la conciencia de desempeñar un papel alejado de los grandes eventos de la historia oficial (Araujo 1997: 37). Este aspecto se suma al carácter de feminismo fundamentalmente implícito que ella misma atribuye a la obra. Pogolotti demuestra conciencia de esta singularidad al expresar en una entrevista que "las mujeres, en primer lugar, por nuestro condicionamiento vinculado al hogar, tenemos un modo particular de preservar la memoria. Aunque ya no seamos las mujeres de otro tiempo volcadas básicamente a nuestra función hogareña y reproductora, criadora de hijos" (Gómez-de-Tejada 2017: 195). En el marco de esta visión sobre la memoria femenina, afirma que su escritura autorreferencial no se equipara con otras autobiografías cubanas que responden a un feminismo más directo:

Me resulta muy difícil colocarme en una perspectiva comparativa con los textos de Renée Méndez Capote y Loló de la Torriente. Creo que en [...] Méndez Capote [...], sí hay una afirmación, en la escritura, de su voluntad de ser. [...] fue una persona que desafió todos los convencionalismos durante toda su vida. Y lo hizo, creo, a partir de su condición de mujer. Loló de la Torriente fue una persona de una formación más política, que además en un momento de su vida asumió el feminismo como una militancia. [...] Yo, por lo menos conscientemente, no tomé como referencia ninguna autobiografía que hubiera leído anteriormente (Gómez-de-Tejada 2017: 196-197).

Más allá de la problematización genérica, el mecanismo discursivo por el que el sujeto autobiográfico se resta relevancia a sí mismo y que atraviesa el texto como una constante se relaciona estrechamente con el concepto de acción grupal dominante en la sociedad socialista, que privilegia el conjunto por encima de la individualidad. Althusser (2005) expresa con vehemencia que "la tradición marxista se ha negado a decir que es el 'hombre' quien hace la historia. [..., puesto que] esta expresión es explotada por la ideología burguesa que la utiliza para combatir [...] la expresión verdadera y vital para el proletariado: son las masas las que hacen la historia" (Althusser 21). De este modo, Pogolotti demuestra una firme voluntad intelectual de ostentar este papel secundario. En definitiva, a pesar de la relevancia alcanzada en el desarrollo cultural y educativo del país, envuelto en el ideario revolucionario hacia cuya gesta muestra una tenaz lealtad, el sujeto autobiográfico diluye retóricamente el propio protagonismo en la acción colectiva preconizada por Fidel Castro y el Che en consonancia con las teorías marxistas-leninistas. ${ }^{21}$

${ }^{21}$ Bacallao-Pino (2015) analiza las tensiones entre lo individual y lo colectivo en las relaciones entre el intelectual 
A pesar de la claridad en cuanto al compromiso socialista que emana del yo enunciado, el camino que muestra no está exento de dificultades y frustraciones. En la pintura El intelectual (1936), de Marcelo Pogolotti, la hija adivina condensados los peligros y la naturaleza de la misión del intelectual que ante la página en blanco se debate por cumplir su tarea (Pogolotti 292). La lealtad no impide el relato de ciertos desengańos y ansiedades, de una mirada crítica que se enuncia como camino de integridad vinculado a un riguroso examen de conciencia. En directa correspondencia con las sucesivas definiciones que dibujaron la figura del intelectual y la naturaleza del compromiso estético o revolucionario que debía ser asumido, Pogolotti reflexiona sobre cómo debió soportar la marca del pecado original de los intelectuales que se habían incorporado al triunfo de los guerrilleros sin haber sostenido las armas; y el rechazo que sus orígenes burgueses y letrados despertaban en otros compañeros de destino. Desde la teoría marxista, tal y como expresa Althusser en La filosofía como arma de la revolución (1968), este recelo se fundamenta en la concepción de que el intelectual es siempre un pequeñoburgués y -citando a Lenin y a Gramsci- que tan solo "una revolución radical en sus ideas, una reeducación larga, dolorosa y difícil. Una lucha sin término, tanto exterior como interior" le permite excepcionalmente pasar a "posiciones de clase proletarias" venciendo el instinto de clase burguesa que le es propio (Althuser 1213). Ante la afirmación de que solo la clase proletaria es ciertamente revolucionaria, el intelectual de ascendencia burguesa se focaliza desde una mirada prejuiciada en el contexto de la revolución.

En el capítulo "Eres una pequeñoburquesa con buenas intenciones", Pogolotti retoma la etiqueta que le fue impuesta por los integrantes de la Juventud Socialista en el marco de los debates preelectorales a la Federación Estudiantil Universitaria (FEU) en los años cincuenta y la confronta con el momento en que es admitida en el Partido en 1965, año de la fundación del Comité Central del Partido Comunista de Cuba. Entre estos dos polos temporales y -fiel a su retórica intertextual-apoyado en la referencia del drama sartriano Las manos sucias (1947), el sujeto enunciador analiza con una apesadumbrada meticulosidad la marca pequeńoburguesa, lo que le permite defender la legítima participación del yo enunciado en el proceso revolucionario:

Tardé mucho en descifrar el veredicto, en extraer granos de verdad de la estereotipada condena. Intelectual sí, ese había sido mi proyecto de vida. El tono y el contexto revelaban la subestimación implícita por la especie. Esa marca insalvable abría una fisura, fuente de malos entendidos recurrentes en el diálogo necesario entre intelectuales y políticos.

Aun más difícil de superar, casi pecado original, era el estigma de "pequeñoburguesa" (Pogolotti 153).

y el poder a través de diferentes etapas del proceso revolucionario en Cuba. 
La prejuiciosa condena recibida en el marco de las elecciones estudiantiles se diluye con la entrada al Partido en los ańos febriles de la Revolución donde aún cierta heterodoxia intelectual es permitida. Pogolotti declara enfáticamente que en su "elección como trabajadora ejemplar, el tema del origen clasista no asomó por parte alguna. Fueron conversaciones respetuosas, sin el menor cariz de un interrogativo programado. [...] No pasé por las horcas caudinas de una rendición de cuentas" (Pogolotti 161). Opone la polaridad de la tesis sartreana desarrollada en Las manos sucias -donde "los caminos de la redención [...] estaban vedados" al intelectual (Pogolotti 153) y se enfrentan irreconciliables la razón o la pasión, la acción política o el idealismo indolente, la ética de la responsabilidad o la ética de la convicción- a "la totalidad del ser"; de su ser, que desde el examen de conciencia personal ligado al compromiso revolucionario, se funde en "pasión y raciocinio" (Pogolotti 161). ${ }^{22}$ En este rasgo, propio de una postura intelectual particular y frente al "político profesional" reconoce haber conservado "un granito de insensatez [que la ha] salvado de la amargura, del escepticismo y el desengaño" (Pogolotti 163).

Si la filiación intelectual se declara irrenunciable, en su caso, el estigma de pequeñoburguesa es refutado mediante diversos recursos. Primero, se matiza con el distanciamiento a través de la relativización de sus orígenes dentro de ese sector. Con este fin, vuelve a la infancia para insertarse en el primero de los dos tipos en que divide la pequeña burguesía de Giaveno: "Uno de ellos mostraba el apego a la virtud del trabajo. El otro exhibía el apetito sin límites por el dinero, el afán por atesorar bienes materiales y el empeño por escalar posiciones, atrincherados en prejuicios y convencionalismos, reducto infranqueable de las ideas más retrogradas" (Pogolotti 154). En segundo lugar, detalla su formación en el entorno paterno vanguardista y bohemio donde los hábitos burgueses eran rechazados sistemáticamente. Por último, se ofrece el espacio universitario como propicio para la educación en una realidad práctica que disuelve la excesiva ingenuidad del idealismo de su primera juventud.

Las relaciones entre la intelectualidad y el poder continúan en el capítulo "Los mármoles de Sarrá", donde focaliza especialmente el periodo durante el que ocupa la presidencia del Consejo Asesor del ministro de Cultura, Armando Hart Dávalos. ${ }^{23}$ Según afirma, esta etapa supuso un paréntesis en la labor discreta y diaria habitual, y una breve incorporación al "complejo entramado de la política real" (Pogolotti 2011: 224). En estas

\footnotetext{
${ }^{22}$ López Restrepo (2006) toma como punto de partida Las manos sucias de Sartre para abordar el sentido de esta expresión en la acción política de los gobiernos. A lo largo de su argumentación, explica cómo "Weber [...] profundiza en la condición del buen hombre que tiene las 'manos sucias'. Su argumento parte de considerar que toda acción éticamente orientada puede ajustarse a dos criterios distintos: la 'ética de la convicción' y la 'ética de la responsabilidad'. La ética de la convicción está fundada en creencias y quien actúa de acuerdo con ella no se preocupa de los efectos de sus acciones; en cambio, la ética de la responsabilidad tiene en cuenta las consecuencias de la acción" (Weber 1967; cit. en López Restrepo 2006: 161).

${ }^{23}$ El Ministerio de Cultura se funda el 3 de diciembre de 1976 con Hart, que había sido ministro de Educación (desde el inicio del Gobierno revolucionario hasta 1965), al frente del organismo. Ejercerá este cargo hasta 1997 (Gallardo-Saborido 2009: 229).
} 
páginas cobra especial relieve la reflexión en torno a las tensiones entre intelectuales y revolución: ${ }^{24}$ los pasos traumáticos y sucesivos que marcaron el tránsito "del intelectual comprometido al intelectual revolucionario" al que se le exigía la politización o la acción directa revolucionaria (Gilman 160). En el capítulo siguiente, "Los escritores y artistas en el tiempo de la calabaza", se sitúa en un momento inmediato al presente de la escritura, es decir, al Periodo Especial. La designación figurativa que asocia la situación cubana durante esta etapa a dicho alimento anticipa las transformaciones sociales marcadas por la carestía económica y el desengaño ideológico que cundieron por el país a partir de la caída del bloque soviético en 1989:

Fulminante, la pérdida de los mercados socialistas desencadenó una crisis con visos de bancarrota. [...] El buey sustituyó al tractor. Los componentes químicos de los fertilizantes, la producción fabril, incluido el libro, desaparecieron. [...] La falta de combustible hundía al país en interminables apagones. En 1994, llegamos a lo más profundo del abismo.

Cada noche, con frugalidad monástica, sin el consuelo de la oración, en el comedor heredado de mis mayores yo me instalaba a ingerir mi plato de calabaza (Pogolotti 2011: 249).

En estos párrafos sobre la crisis de los noventa, sintéticamente, con tono crítico y abierto, aborda la grisura dramática del parametraje y la homofobia; las sucesivas oleadas migratorias que dieron lugar a una fuerte y variada comunidad cubana en el exterior; las formas de la supervivencia en medio de los problemas cotidianos ante la falta de lo básico. Junto a ello, subraya cómo en el seno de las dificultades, trabajosamente, se generó un cierto resurgimiento cultural que tendió puentes hacia el exilio, permitió lazos con el mercado internacional, y se benefició de la útil labor de las revistas literarias. Al final del capítulo, la autora argumenta de qué manera la ansiedad por cubrir las necesidades más perentorias canceló las vías de análisis de la sociedad cubana y se cayó en el peligro del escepticismo o incluso del cinismo de la parodia. En medio de este panorama general, el comienzo de la tarea autobiográfica se vincula a la reflexión crítica, el trabajo intelectual, la austeridad y la plenitud anímica que se proyectan como salvación personal, y quizás, implícitamente, como camino colectivo:

\footnotetext{
${ }^{24}$ Las relaciones de los escritores cubanos afines a la Revolución han transitado por diversas etapas desde el comienzo de esta. La integración entusiasta en la política cultural en los primeros años sesenta, frecuentemente condensada en la actividad de Lunes de Revolución, entre otras empresas culturales, se vio condicionada por los (des)ajustes que supusieron las "Palabras a los intelectuales" (1961), dictadas por Fidel Castro, las directrices establecidas por el I Congreso Nacional de Cultura (14 y 16 de diciembre de 1962) y las expectativas marcadas por el texto de Ernesto "Che" Guevara titulado "El socialismo y el hombre en Cuba" (1965). En los años setenta, se produce una mayor institucionalización a partir del I Congreso Nacional de Educación y Cultura (23 y 30 de abril de 1971), que se concreta en el refuerzo de las posiciones antiintelectualistas, que exigían un compromiso revolucionario nítido y profundo.
} 
Empantanado en su inmovilidad, el mundo socialista había renunciado a formular preguntas ante una sociedad que, cuerpo viviente, descartaba células muertas y adoptaba las recién nacidas. Vulnerando principios fundamentales del marxismo, abandonó las herramientas requeridas para el estudio de la realidad. Olvidó su propósito supremo, la liberación de la persona con vistas al logro de una creciente plenitud.

[...] Desde mi yo más recóndito, descubrí el crecimiento de la dimensión espiritual del ser en una ascesis cada vez más intensa. Despojada de lo superfluo, el mundo me devuelve un fulgor de felicidad posible en el goce de los trabajos y los días. Entregada a múltiples labores cotidianas, con antenas dispuestas a recibir todos los mensajes, puedo empezar a escribir mis memorias (Pogolotti 258-259).

La mirada crítica se cierra con el examen de conciencia postrero que la autora construye como capítulo final. Toda esta parte supone una introspección realizada en el presente inmediato de la escritura, donde el yo enunciador y el yo enunciado se identifican en el tiempo de la reflexión sobre el pasado y desde la certidumbre serena del fin de un proyecto. Pogolotti confiesa explícitamente la conciencia de que su biografía -el cuerpo histórico-textual- ha sido tallada por cada una de las acciones decisivas de Fidel Castro. En este sentido, traza el paralelo cronológico entre la figura del máximo líder y la propia en un deseo de marcar las concomitancias ideológicas, éticas y generacionales. Por ello, en el capítulo final, reservado por la autora especialmente al examen de conciencia que tiene al propio yo como sujeto central de la enunciación introspectiva, puede incluirse un conciso panorama evocador del dirigente revolucionario:

Involucrada por entero en la Revolución. [...] Reconozco en Fidel y en mí similar angustia ante la certidumbre de un tiempo que se precipita en acontecimientos de alcance planetario que atañen a la vida de todos [...].

[...] Fidel Castro, a no dudarlo, verdadero protagonista de la hazaña histórica en la segunda mitad del siglo XX. Su aparición marcó nuestro destino, y su presencia, aun desde la distancia física, a pesar de la inexistencia de un diálogo personal, contribuyó a modelar mi biografía, muy diferente, sin dudas, de no haberse producido el triunfo revolucionario de 1959 (Pogolotti 292-294).

En definitiva, Dinosauria soy se erige desde la conceptualización de la autobiografía como simulacro escritural. Pogolotti no pretende entregar la vida empírica trasladada íntegra al texto. La autora, desde la certeza de esta imposibilidad, procura una reconstrucción veraz dirigida a un tú con el deseo de cumplir una vocación de compromiso intelectual. Este interés se plasma, por un lado, en la narración del proceso de inmersión en proyectos culturales y educativos dentro del trazado revolucionario y, por otro lado, en el trasfondo semántico que proporciona al resto de itinerarios discursivos de la obra, en mayor o menor medida atravesados por él. A partir de la explicitación retórica de un discreto protagonismo 
en la época, escribe su autobiografía como un servicio a la Revolución y como respuesta a una petición externa en un momento en que la crisis del Periodo Especial aún estaba muy presente. No obstante, en consonancia con el examen de conciencia que profesa ritualmente, la escritura autobiográfica se vuelve cauce introspectivo de pretendido autoconocimiento y de conciliación con la otredad.

En el prólogo que Pogolotti escribió para la edición de Por el camino de Swann de Proust (al que pertenece el fragmento utilizado como exergo en este trabajo), seńala cómo los acontecimientos que contribuyen a cambiar la historia dejan marcas imperecederas en la piel. De este modo, cada uno de los hitos del proceso revolucionario cubano se encarna como cicatriz en el propio mapa corporal, huellas de un periplo existencial vivido desde la conciencia de la historia y el compromiso intelectual.

\section{ObRas Citadas}

Althusser, Louis. 2005. La filosofía como arma de la revolución. México: Siglo XXI.

Alvarez-Borland, Isabel. 1998. Cuban-American literature or exile: from person to persona. Charlotesville and London: University Press of Virginia.

Araújo, Nara. 1997. "La autobiografía femenina ¿un género diferente?”. Unión. Revista de Literatura y Arte 26: 35-39.

Bacallao-Pino, Lázaro M. 2015. "El péndulo de Foucault: los intelectuales y la Revolución Cubana”. Andamios. Revista de Investigación Social 12, 27: 53-75.

Bourdieu, Pierre. 1997. Las reglas del arte. Génesis y estructura del campo literario. Barcelona: Anagrama.

Bruss, Elisabeth W. 1991. "Actos literarios”. Anthropos (Suplemento) 29: 62-79.

Casaus, Víctor. 1986. "Defensa del testimonio". Testimonio y Literatura. René Jara y Hernán Vidal, eds. Minneapolis, MN: Institute for the Study of Ideologies and Literature. 324-333.

Castro, Fidel. 1959. "Discurso pronunciado por el comandante Fidel Castro Ruz, a su llegada a La Habana, en Ciudad Libertad, el 8 de enero de 1959”. Web. . 1971. "Discurso pronunciado por el comandante Fidel Castro Ruz, primer secretario del Comité Central del Partido Comunista de Cuba y primer ministro del Gobierno revolucionario, en la clausura del Primer Congreso Nacional de Educación y Cultura, efectuado en el teatro de la CTC, el 30 de abril de 1971”. Web.

Clark, Stephen J. 1999. Autobiografía y Revolución en Cuba. Barquisimeto: Alcaldía del Municipio Iribarren, Fondo Editorial "Río Cenizo".

Colomer, Josep M. 1998. "Salida, voz y hostilidad en Cuba”. América Latina Hoy 18: 5-17.

Cremata-Ferrán, Mario. 2017. "Ventana infinita hacia la luz. Graziella Pogolotti [Entrevista].” Mario Cremata Ferrán. La voluntad de prevalecer. La Habana: Boloña. 197-210.

Fernández, Damián J. 2005. “Cuba Transnational. Introduction”. Ed. Damián J Fernández. Cuba Transnational. Gainsville, FL: University Press of Florida. xviii-xviii. 
Freitas Reis, Livia de. 1997. "Autobiografía, testimonio, ficción: una relación delicada”. Unión IX, 26: 43-47.

Gallardo-Saborido, Emilio. 2009. El martillo y el espejo: directrices de la politica cultural cubana (1959-1976). Madrid: CSIC.

Gilman, Claudia. 2003. Entre la pluma y el fusil. Debates y dilemas del escritor revolucionario en América Latina. Buenos Aires: Siglo XXI Editores Argentina.

Gómez-de-Tejada, Jesús. 2017. "Entrevista a Graziella Pogolotti, autora de Dinosauria soy: Memorias (2011)". Cuadernos del Hipogrifo 7-8: 191-200.

Guevara, Ernesto Che. 1975. El socialismo y el hombre en Cuba. Barcelona: Anagrama.

Hirschman, Albert O. 1977. Salida, voz y lealtad: Respuestas al deterioro de empresas, organizaciones y estados. México: Fondo de Cultura Económica.

López Restrepo, Andrés. 2006. "El problema de las 'manos sucias' y la política”. Ciencia Politica 1, 2: 179-212. Web.

Loureiro, Ángel G. 2006. "Autobiografía: El rehén singular y la oreja”. La ansiedad autorial. Formación de la autoría femenina en América Latina: los textos autobiográficos. Márgara Russotto, ed. Caracas: Equinoccio, Universidad Simón Bolívar. 19-38.

Loureiro, Ángel G. 1994. "Diferencias feministas". El gran desafí: feminismos, autobiografía y postmodernidad. Ángel G. Loureiro, ed. Madrid: Megazul-Endymion. 9-32.

Miranda, Olivia. 2008. "El testimonio". Historia de la literatura cubana. La Revolución (1959-1988). Sergio Chapel y Cira Romero, ed. Vol. III. La Habana: Letras Cubanas. 507-520.

Pérez-Hernández, Reinier. 2016. "De la actualización del paradigma autobiográfico en la literatura cubana". Romanische Studien 3: 27-59. Web.

Pogolotti, Graziella. 2011. Dinosauria soy. Memorias. La Habana: Unión. . 2006. Polémicas culturales de los 60. Selec. y pról. Graziella Pogolotti. La Habana: Letras Cubanas. . 2001a. "La bulla". Revolución y Cultura 1: 49-51. . 2001b. "El paso de las flotas". Revolución y Cultura 2: 53-55. 2001c. "La familia se retrata". Revolución y Cultura 3: 54-55. . 2001d. "Desde la colina". Revolución y cultura 4: 53-55. 2001e. "Reina del Mar". Revolución y Cultura 5-6: 78-81. 2006. "Zizou". Revolución y Cultura 1: 4-6.

Proust, Marcel. 1987. Por el camino de Swann. Pról. Graziella Pogolotti. La Habana: Arte y Literatura.

Rojas, Rafael. 2006. Tumbas sin sosiego. Revolución, disidencia y exilio del intelectual cubano. Barcelona: Anagrama.

Scarano, Laura. 1997. "El sujeto autobiográfico y su diáspora, protocolos de lectura”. Orbis Tertius 2.4: 151-166.

Smith, Sidonie. 1991. "Hacia una poética de la autobiografía de mujeres". Anthropos (Suplemento) 29: 93-106.

Smith, Sidonie y Julia Watson. 2001. Reading Autobiographies. A Guide for Interpreting Life 
ESTUDIOS FILOLÓGICOS

Narrative. Minneapolis, MN; London: University of Minnesota Press.

Stendhal. 1971. La Cartuja de Parma. Pról. Graziella Pogolotti. La Habana: Instituto Cubano del Libro.

Weber, Max. 1967. "La política como vocación”. El politico y el científico. Madrid: Alianza. 160-179.

Weimer, Tania N. 2008. La diáspora cubana en México: terceros espacios y miradas excéntricas. Nueva York: Peter Lang. 